\title{
0 Direito Sumular
}

\section{Ministro JOSÉ PEREIRA LIRA \\ Ex-Presidente do Tribunal de Contas da União e atual Presidente do Instituto dos Advogados Brasileiros - DF}

O Direito Legislado tem a sua raiz no Direito Consuetudinário, como é de todos sabido, embora também se destine a paralisar, corrigir ou mesmo proibir praxes e usanças, ocasional ou definitivamente, reputadas condenáveis.

Costumeira, ou legislada nas suas múltiplas formas, a norma assume a fisionomia de Direito Aplicado, com intensidades diferenciadas, tendo por base a jurisprudência ou a lei.

Se o Direito Aplicado esteia-se na lei, surge a vexata quaestio de saber se o costume jurídico pode operar contra a lei-tema que é enfrentado, diretamente, pelos partidários do Direito Livre, e, obliquamente, pelos sequazes da interpretação construtiva (a "Construction", dos anglo-saxões).

Se o Direito Aplicado, porém, firmava-se na jurisprudência, gradualiza-se a sua consistência, a depender do teor, da idade, da iteratividade da "jurisprudência dita assentada", e ainda da autoridade e da hierarquia dos judicantes, da uniformidade (e freqüência) das decisões, e da sua aceitação pelos doutôres, no campo da doutrina, e também do assentimento da comunidade.

A história sincera das instituições jurídicas pode ser extraída dos "depósitos de jurisprudência", com veracidade maior do que nos acervos de textos legislados.

Eis por que essa é "a hora e a vez" da "jurisprudência", que está deixando de ser um armazém, um paiol, "um estoque", desordenado, para vir, futuramente, a decantar-se na jurisprudência científica, a caminho da "ordenação", segundo os princípios da "informática" - por ora, em processos de "indexação" convencional, pautada em "palavras-chaves", e, amanhã, em têrmos de "ordenação eletrônica", segundo a "informática avançada". 


\section{OS REPOSITÓRIOS DE JURISPRUDENCIA}

As tentativas históricas, para oferecer a juristas (professôres, advogados, magistrados etc.) "repositórios" de "julgados" brasileiros - essas tentativas tiveram como ponto alto, no passado remoto, a "revista", "O Direito", de J.J. do Monte, desde a Côrte Imperial (1873 a 1913), ao lado de outras publicações que resultaram efêmeras e sem a mesma aceitação nos meios jurídicos.

Diversas "revistas" marcaram época, inclusive, já no período republicano, uma delas portando um título da maior divulgação, e que resultou num rumoroso pleito judicial, em que foi parte a União Federal.

Bento de Faria, depois Ministro da Côrte Suprema, fundou e dirigiu, com êxito marcante, a mui reputada "Revista de Direito".

Edgar Costa, o magistrado insigne, que veio a ocupar com brilho invulgar uma sede curul no STF, dirigira, largo tempo, uma publicação utilissima, intitulada "Arquivo Judiciário", prestando serviços inestimáveis à família dos militantes do Direito.

Eduardo Espínola, também alçado às culminâncias do Poder Judiciário - com fundar uma publicação jurisprudencial não vislumbrara desdouro em coletar "julgados", comentá-los e enfeixá-los num periódico especializado, que editou, em bases exemplares, como igualmente o fizera Clóvis Bevilaqua.

Astolfo Rezende manteve, com sacrifícios e galhardia inusitados, uma esplêndida "revista", largamente citada, também especializando a jurisprudência.

Nilo Vasconcelos marcou, por época dilatada, o seu comprovado idealismo, realizando, em molde ímpar, uma "Revista de Crítica Judiciária".

Muitas outras iniciativas, descontinuadas, embora com o paraninfado de nomes de real e reconhecida autoridade, vieram à luz da publicidade - e perpetuaram decisões de suma importância - e, de muito, servirão para que o historiador das nossas instituições sócio-jurídicas possa "levantar", no futuro, o nascimento, a vida, as mutações e o desaparecimento de institutos que regeram de fato a tessitura político-administrativa do nosso País, mantendo esta, transformando-a ou adoecendo-a de obsolescência.

Pelo seu caráter empresarial, de que Ihes adveio milagrosa continuidade, são de registrar: a "Revista Forense", fundada por 
Estevão Pinto e Mendes Pimentel e continuada, entre outros, por Carlos Medeiros Silva e Bilac Pinto, dois nomes imarcesciveis na história da jurisprudência pátria; e a "Revista dos Tribunais", dirigida por diversos, incluindo Plínio Barreto e Noé Azevedo, a constituir cimos da cordilheira.

Tôdas essas publicações tinham e têm caráter eclético, globalizando Doutrina, Legislação e Jurisprudência, para melhor servir às solicitações do mundo jurídico - a que prestaram e vêm prestando serviços incontáveis, nas Capitais judiciárias dêste imenso Brasil e, sobretudo, nas esquecidas comarcas interioranas.

Como se não propõe, aqui, a apresentação de uma "resenha" completa dos "materiais dispersos", basta referir as edições estaduais das "Revistas do Fôro", espalhadas em todo o território nacional, condensando e fixando os "julgados" dos tribunais locais; e a, já, imensa coorte dos órgãos oficiais de tribunais, de vária espécie, das Procuradorias e Serviços Jurídicos de Entes Públicos, de Ministérios, de órgãos estatais e paraestatais, onde são conservados, em letra de fôrma, fatos da maior relevância para a nossa evolução sócio-jurídica.

Merecem registradas à parte, como exemplares repositórios, entre outros, a "Revista do Tribunal Federal de Recursos", a "Revista do Serviço Público, do DASP; os "Arquivos", do Ministério da Justiça; a "Revista de Informação Legislativa", do Senado Federal; a "Revista de Jurisprudência", do Tribunal de Justiça do Estado da Guanabara; a "Revista de Direito da Procuradoria-Geral", do Estado da Guanabara; a "Jurídica", do Instituto do Açúcar e do Álcool; a publicação "Minas Forense"; a "Revista da Faculdade de Direito da Universidade de São Paulo"; a "Revista de Direito Administrativo"; a "Revista Jurídica da Faculdade de Direito da Universidade do Brasil", a "Revista Jurídica da Procuradoria-Geral do Distrito Federal"; a "Revista do Conselho Penitenciário do Distrito Federal; a Revista de Direito da Procuradoria-Geral do Estado de Goiás"; e a "Revista do Tribunal de Justiça do Distrito Federal" - "Doutrina e Jurisprudência" - the last, but not the least".

Pela sua continuidade tradicional, ao lado de outras publicações locais, inclusive a recém-fundada "Revista OAB", do Distrito Federal, órgão da Ordem dos Advogados do Brasil, em Brasília - , figura a "Revista do Instituto dos Advogados Brasileiros" que representa um esfôrço hercúleo através de anos de benemerência indisputável.

Muitos outros "arquivos" de jurisprudência há pelos Estados, como para exemplificar, de memória, o "Paraná Judiciário", 
"Jurisprudência e Doutrina" (Ceará), e a antiga "Revista do Fôro", do Estado da Paraíba, além de publicações de universidades várias, como a excelente "Revista da Universidade Federal de Goiás".

O caráter eclético começará a orientar-se, em poucas dessas publicações, para a especialização jurisprudencial, com tendência à exclusividade, desde a "Revista de Crítica Judiciária", de Nilo Vasconcelos; mas veio a acentuar-se, depois, sob a forma de "indexário", com Agripino Veado; e com inúmeros "repertórios" e "manuais de jurisprudência", não sendo de omitirse o nome festejado de Otávio Kelly, um trabalhador infatigável e de competência a mais notória.

Contribuição não despicienda foi trazida à colação por um sem conto de magistrados, em publicando "Votos e Acórdãos" e dando "comunicação", ao meio jurídico, dos seus esforços de "Voluntários", na "Construção da Jurisprudência assentada".

A jurisprudência, contudo, se já não era um mero tecido conjuntivo, de compreensivel tenuidade, não passava da densidade de tecido cartilaginoso, não se the atribuindo, ainda, a compacidade da resistência óssea.

Era negada, como fonte de Direito, e sem o prestígio da obrigatoriedade.

"ENFIN, MALHERBE VINT"! A "SÚMULA" DO STF

Êsse verso de Boileau - parte de um alexandrino, històricamente injusto (por isso que François de Villon fôra esquecido) - lembraria, na história jurisprudencial brasileira, a figura, a todos os títulos, pioneira, de então Ministro do Supremo Tribunal Federal Victor Nunes Leal.

Os nossos alunos do Curso de Especialização de Jurisprudência Civil, na Universidade de Brasília (UnB), em desincumbência de "tarefa" do nosso "Laboratório de Jurisprudência", gravaram uma recente entrevista com o "Pai da Súmula", em que êle, de viva voz, fornece o "assento de batismo" da Súmula:

"A Súmula foi criada há alguns anos (nota: 1963). E previa-se o acréscimo de novos "enunciados", cada ano ou mesmo com periodicidade menor. Com a Revolução e a modificação profunda de vários institutos 
jurídicos, o Tribunal achou prudente fazer uma pausa, porque a própria existência da Súmula poderia ser contestada e negada pela nova legislação que se editasse.

O que se verificou, no entanto, após alguns anos, foi a consagração constitucional da competência do STF para fazer "súmula".

De modo que o Tribunal já retomou, com a supervisão do Ministro Aliomar Baleeiro, a elaboração de novos "enunciados"; e uma centena dêles foi, há pouco, acrescentada à Súmula, sendo de esperar que o Tribunal prossiga no mesmo ritmo que vem atestando atualmente.

Hoje, a partir da Reforma de 1967, por iniciativa do então Ministro da Justiça, Carlos Medeiros Silva, que fôra Ministro do STF, hoje, "a Súmula tem assento na própria Constituição que autoriza o STF a deferir "normas de Processo", perante êle.

Como a Súmula tem efeitos processuais, que são definidos no Regimento, essas "normas", hoje, são equiparáveis, no âmbito do Supremo Tribunal Federal, às normas de Direito Processual, e são da competência privativa do STF."

\section{UM "ACHADO" BRASILEIRO}

A "Súmula" - invenção brasileira, diferençada do stare decisis e do restatement of the law - deve ser reconhecida como uma "revolução", ainda não inteiramente vislumbrada pelos observadores superficiais.

Dela tratamos, cumpridamente, como do "Nôvo Regimento do Supremo Tribunal Federal" (1970), em o nosso pequeno ensaio "Manifesto Contra a Rotina".

O que, porém, é adequado sublinhar, aqui, cifra-se em que:

19) O STF tem, agora, "atribuições legislativas", por fôrça do artigo 120, parágrafo único, letra c, da Constituição, e, ainda, nos têrmos do artigo 10 do Regimento do STF (1970);

20) por fôrça da sua competência, o STF edita "enunciados", altera-os e revoga-os, os quais, editados ou alterados, passam a constituir provisões legais da República, integradas 
no "direito federal", o qual é defendido por meio do recurso extraordinário, a benefício da sua unidade;

3o) o conjunto dos "enunciados" constitui a "Súmula da Jurisprudência Predominante do Supremo Tribunal Federal", de caráter obrigatório, direto, nos órgãos do STF, no processo e no julgamento dos feitos que lhe são atribuídos pela Constituição da República (art. 1.9); e, obliquamente, ainda de caráter compulsório, mercê do recurso extraordinário, quando cabivel.

Não é adequado fixar, aqui, as dessemelhanças da Súmula brasileira, em frente ao stare decisis e ao restatement of the law de outros povos.

Nem, tampouco, o papel da jurisprudência, na área comparatista.

Não é demasia, contudo, registrar que, no Direito francês, e alhures, tornou-se clássico o livro de Henri Capitant, agora refundido por Léon Julliot de La Morandière e Alex Weill, sob o título "Les Grands Arrêts de la Jurisprudence Civile".

Seguiram-se-Ihe "Os Grandes Julgados da Jurisprudência Comercial", e ainda "Os Grandes Julgados da Jurisprudência Administrativa" etc.

Justificando a iniciativa de Henri Capitant, La Morandière e Weill escreveram, na $4^{\mathrm{a}}$ edição do livro de Capitant:

"Foi preciso, sobretudo, para seguir o ritmo rápido da evolução do nosso Direito, inserir um número bastante elevado de "julgados", nos últimos dez anos (o negrito é do tradutor), definindo questões novas ou dando uma nova orientação à solução de problemas antigos."

E o próprio Henri Capitant, no prefácio à 1 ạ edição do seu livro, então, e ainda hoje, clássico, justificou o papel da jurisprudência:

"A jurisprudência é, com efeito, embora tenha sido contestado, uma fonte de Direito como a lei, ela mesma; e essa fonte torna-se, cada vez mais, abundante, à medida que a lei envelhece.

Sem sair do seu papel de intérprete (o negrito é do tradutor), procurando, nos textos do Código, ou, na sua falta, nos princípios gerais que os dominam, os motivos dos seus julgamentos, os Tribunais criam, a pouco e pouco, um corpo de Direito, uma doutrina que completa, enriquece e emenda (?) (interrogação do tradutor) a obra legislativa. 
Sem essa contribuição constante, sem êsse rejuvenescimento incessante, as leis envelheceriam e pereceriam.

Elas não escapam à decrepitude senão por êsse afluxo de sangue nôvo, por essa vegetação complementar que Ihes traz essa adaptação cotidiana às necessidades do comércio jurídico.

Os juristas contemporâneos compreenderam que sua missão consistia em estudar, em criticar êsse Direito em formação, em deduzi-lo da massa das decisões em que êle se acha enterrado como o mineral no solo; em livrá-lo, das suas escórias; em uma palavra: em sistematizá-lo.

É a êles, com efeito, que incumbe essa missão de correção.

Os magistrados, absorvidos pelo julgamento dos processos que chegam sucessivamente diante dêles, deliberando sôbre espécies sempre variáveis, não podem captar os traços geraís das regras, na elaboração das quais êles participam, não mais que 0 viandante na floresta que não vê o conjunto dela (ainda a sublinha é do tradutor).

E por isso que os Mestres das nossas faculdades debruçam-se, hoje, sôbre as decisões da jurisprudência, como o sábio sôbre a matéria, para perscrutarIhes a composição.

Mas, diferentemente do sábio, que observa as coisas do mundo exterior, o jurista trabalha sôbre uma matéria essencialmente instável e mudável, porque ela é obra da vontade dos homens.

Assim, seu papel não se limita a observar; deve criticar, na ocasião, com vistas a "reparar" (redresser), se possivel, a interpretação que os Tribunais dão aos textos das leis.

Seja como fôr, o jurista não pode, hoje, vangloriar-se de conhecer o Direito senão se êle completa e vivifica o estudo dos textos pelo da jurisprudência."

\section{ORIGINALIDADE DA SÚMULA}

A página antológica que se vem de ler, das mais agudas e percucientes, saída da pena de Henri Capitant, fazíamos distribui-la, cada início de curso, entre os jovens universitários 
que colaboram no "seminário", no "laboratório" e no "Cijur Centro de Informática Jurisprudencial".

Suas "conclusões" são em número de cinco:

1a) a jurisprudência é fonte de Direito;

2a) os Tribunais não devem sair do seu papel de intérprete;

3a) são reconhecidos, contudo, aos Tribunais: a missão, como juristas, de sistematizar a massa das decisões, livrando-as das "escórias", e a de criar um corpo de doutrina, para preparar "a emenda" da obra legislativa;

4a) é reconhecido por Henri Capitant que os magistrados vivem absorvidos pelos julgamentos correntes, não podendo captar os traços gerais das regras em cuja elaboração participam;

$5^{\text {a) }}$ cabe, assim, aos mestres das nossas faculdades debruçar-se sôbre as decisões da jurisprudência, para perscrutar-Ihes a composição, com vistas a "retificar", quando necessário, a interpretação que os Tribunais dão aos textos das leis.

Essa página e essas "conclusões" (que parecem ter sido escritas - e o foram - para o Direito Universal) estão elas, para nós, em parte superadas pela criação, brasileira, da "Súmula da Jurisprudência Predominante do STF", no Direito Pátrio, o qual soube dar um passo a frente na conquista da verdade jurídica.

É assim que a nossa Súmula evitou o imobilismo do stare decisis; pôs-se a salvo da inautenticidade das formulações privadas, manipuladas por particulares, como os discutidos restatement of the law, dos americanos; e, reconhecendo a jurisprudência como efetiva e real fonte de Direito e alçando o papel do magistrado - intérprete, a um grau mais elevado, de construtor de norma - tornou o Supremo Tribunal Federal um co-legislador, com atribuir, aos "enunciados" que edita, e altera (e mesmo suprime, ex autoritate propria) o valor de "texto legal", e a eficácia de "direito federal", protegendo a sua unidade nacional com o recurso extraordinário.

Essa é a originalidade da "Súmula da Jurisprudência Predominante do STF".

FUNCIONALIDADE DA SÚMULA

O "Anexo" ao Regimento do STF (de 1963, em vigor no comêço de 1964) e o Nôvo Regimento do STF (1970) já foram êles, por nós, examinados, em breves ensaios anteriores, para demonstrar a sua perfeita funcionalidade. 
É certo, porém, que não é demais sublinhar, neste ensejo, quão feliz é a observação de La Morandière e Weill, no seu não menos histórico "Prefácio" a "Les Grands Arrêts de la Jurisprudence Civil", quando sugerem dez anos como tempo útil para rever "o passado jurisprudencial".

No caso brasileiro, a Súmula nasceu em 1963, com o "Anexo". A data de 1964 é a da "revolução legislativa".

Trata-se, pois, de jurisprudência nova, nascida, ou confirmada, com os novos textos. O Regimento (1970) não arquivou a jurisprudência antiga. Até mesmo definiu o elenco dos "repertórios oficiais" (art. 95), muitos dêles anosos e poeirentos. Outros, em plena atualidade, como sói acontecer com a autorizadíssima Revista Trimestral da Jurisprudência, do STF.

O "passado jurisprudencial", remoto, interessará ao campo dos historiadores das instituições. em 1964.

Para o direito a aplicar, via de regra, o horizonte começa

De mais a mais, a jurisprudência é o contrário do vinho, que êsse, sim, quanto mais velho, melhor.

Portanto - a Súmula não faz arqueologia; obedece, talvez preferencialmente, à regra da década, e não fica à deriva, como no stare decisis, perdido o "pesquisador" na bruma do tempo e na poeira dos arquivos.

Além de lavrar campo relativamente nôvo, o "pesquisador" é conduzido pelo "sumulador", para caminhos já não polêmicos, para o terreno não mais movediço de dúvidas já solvidas, e dentro de entesouramento setorial recente.

A síntese virá, depois, com a, por agora, quimera de um Thesaurus Jurisprudentiae.

A "Suma" das "Súmulas", essa, segundo o conselho de Henri Capitant, caberá aos mestres das nossas universidades, com a integração nelas e nos seus "ordenadores eletrônicos", do tríptico:

$$
\text { Legislação - Jurisprudência - Doutrina. }
$$

Aí estão os exemplos, incentivadores, do Canadá e da Bélgica.

OS "PASSOS" DA "OPERAÇÃO SÚMULA"

Essa é matéria de um "programa" que, aliás, foi por nós traçado para a Universidade de Brasília (UnB). 

viamente:

Dessa "Operação Súmula", os "passos" didáticos são òb-

a) Coleta

b) Classificação

c) Indexação Convencional (e depois Eletrônica)

d) Ordenação (palavras-chaves)

e) Análise - Crítica.

Reunidos os materiais, cumpridos os "passos", e após a análise crítica, os juristas procederão à pré-sumulação, com vistas ao Direito constituendo e às reformas legislativas, notadamente às codificações.

Parece prudente deixar a "Sumulação", pròpriamente dita, à competência exclusiva do STF, e, posteriormente, estendê-la a outros órgãos judiciários, de cúpula, para não incorrer nos desacertos em que se verificou fértil o "restatement", dos americanos, e de que se não puderam resguardar, antes do Código Civil, os nossos "consolidadores".

Será uma "consolidação judicial" à maneira do "Pretor romano", com autoridade, a mais plena, e com características a recordar o Edictum Perpetuum, de fácil reformabilidade.

\section{LEIS QUE "VINGAM" LEIS QUE "NAO VINGAM"}

"Fazer leis", mais ou menos artificiais, não é tarefa das menos disputadas. Há sempre "aprendizes de feiticeiro".

No entanto, descobrir "a lei" dentro do cipoal dos textos semi-obseletos; "batear" as pepitas de ouro do Justo, na ganga impura das torrentes da Vida; ou, como diz Capitant, no "Prefácio" histórico: desenterrar do solo o mineral nobre e limpá-lo das "escórias"; essa é tarefa que conta e que se impõe, para conseguir a fundação da jurisprudência científica.

Há, dessarte, "os fazedores de leis" e "os descobridores da lei". Até "os aprendizes" se aventuram à primeira atividade; a segunda é privilégio dos nossos mestres.

"AS FERRAMENTAS"

Mas os nossos mestres não poderão trabalhar sem "as ferramentas", sem a "matéria-prima" acumulada, sem o "canteiro de obra", sem os "artesões especializados". 
Esta última consideração salteou o nosso espírito, ao let 0 art. 95 do Regimento do STF que fixou quais os "repositórios oficiais" da jurisprudência do STF, bem como ao utilizar as numerosas coletâneas preparadas por Jardel Noronha e Odaléa Martins que estão praticando a benemerência editorial de colocar ao alcance de estudiosos e estudantes, de forma ordenada, as lições magistrais do Pretório Excelso, nesta década jurídica, de tanta repercussão na vida do Direito Pátrio.

Essa operosa parceria editorial começou, com êxito surpreendente, "o passo inicial" da "garimpagem".

Que apareçam os "artesãos especializados" para trabalhar - ouro e o diamante dos nossos veios jurídicos, facilitando a missão dos nossos mestres na "construção" do Direito Sumular, que é uma criação brasileira.

O "Direito Sumular" será a meta da "década 70 ", a princípio, pelos processos da "informática convencional", e, ao depois, no rumo da "informática eletrônica", ou "indexação avançada".

Quem viver verá, em face do desafio fascinante, que ao Homem impõem, na hora presente, o progresso da tecnologia e as conquistas da ciência. 


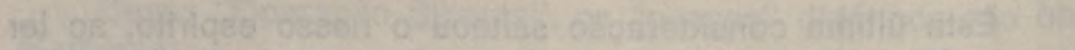

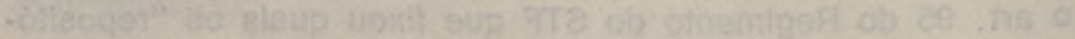

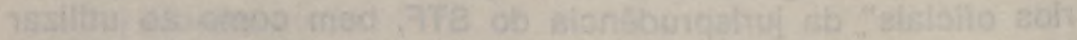

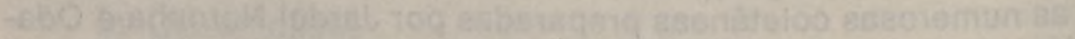

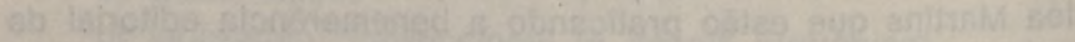

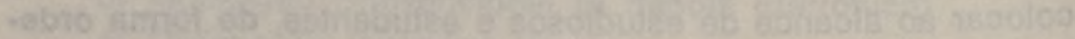

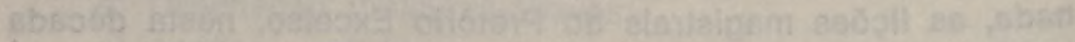

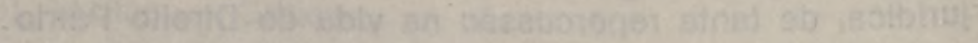

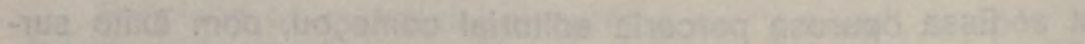

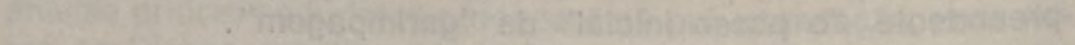

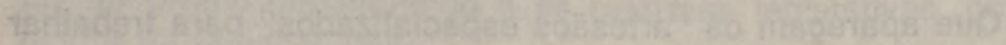

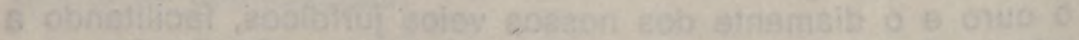

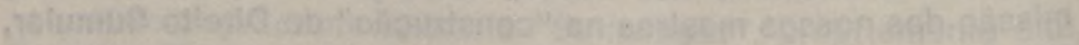

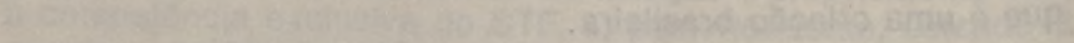
Hixy

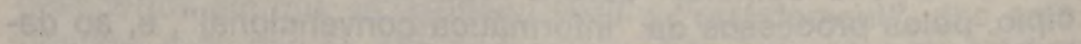

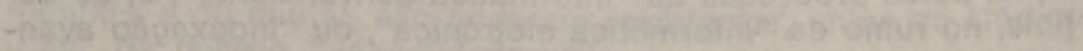
$\cos 6$

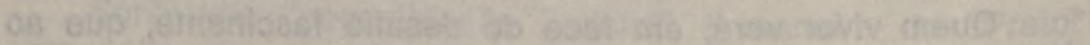
Afogtongo'

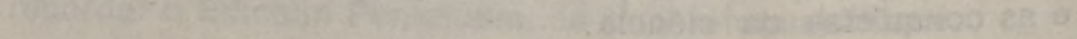

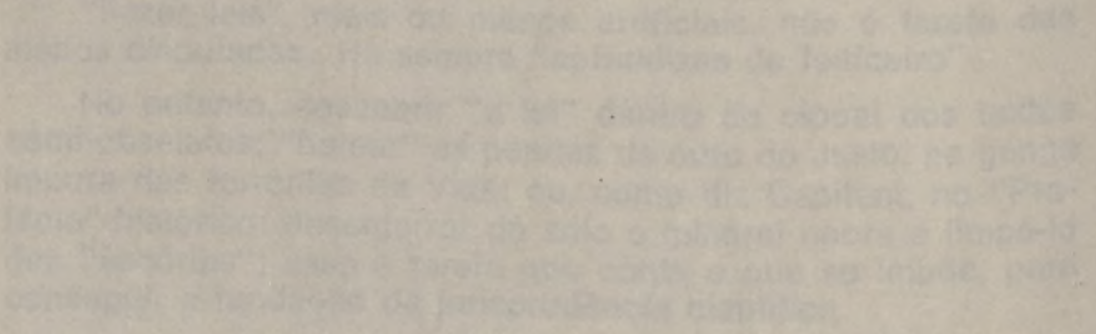

